\title{
Case Files of the University of Massachusetts Fellowship in Medical Toxicology: Three Patients with an Industrial Radiography Source Exposure
}

\author{
Christina Hernon, MD a Edward W. Boyer, MD, PhD a, Doran Christensen, DOb, \\ and Steve Sugarman, MS/Health Physicist ${ }^{\mathrm{b}}$ \\ a University of Massachusetts Memorial Medical Center, Worcester MA \\ b REAC/TS (Radiation Emergency Assistance Center/Training Site), Oak Ridge, TN
}

\section{CASE SERIES}

Three male industrial radiographers, two aged 40 and one aged 63 , performed a routine inspection of an industrial radiography device (IRD). During the course of the inspection, they observed that the radioactive source (a 93.4 curie iridium-192 source) had incompletely retracted into the heavily shielded box. The exposure was reported to a Radiation Safety Officer who calculated the exposure as " 18,000 roentgens to the hands and 8 roentgens to the whole body." Based upon his recommendation, the three patients presented to two local emergency departments (EDs) with a request for blood testing and initial evaluation.

In the ED, all patients had normal physical exams with normal complete blood counts. Medical personnel called the local Poison Control Center to learn if shaking the patients' hands produced exposure to radiation and whether any decontamination was needed. In addition, the Poison Control Center received calls from family members of the exposed patients and from the State Department of Radiation Health.

\section{Why review the management of radiation injury?}

Radiation topics have a greater presence in the public consciousness. In recent years, an increased awareness of potential threats has fueled greater focus on emergency preparedness to "dirty bombs" or potential attacks on nuclear energy sites. Significant occupational hazards involving radiation may also result in significant mortality or morbidity. As recognized specialists in diseases caused by exogenous chemical exposures, Medical Toxicologists and Poison Control Center staff may be asked for recommendations regarding decontamination, management, and prognosis of these patients.

Although nuclear power plants are the obvious occupational radiation exposure environments, other potential sites include medical facilities, research laboratories, and agricultural, industrial and manufacturing sites.

\section{What is an IRD? What is it for, and how does it work?}

Industrial radiography devices (IRDs), also called radiography "cameras", are used commercially to search for defects in piping, metal vessels, and welds. During normal use of the device, a long guide tube is placed inside or outside of a pipe or vessel and radiographic film is placed on the opposite side. The radioactive source, such as iridium-192, is extended within the guide tube to the end, held a few seconds to expose the film, and then retracted back into its heavily shielded, protective box (See Figure 1). Any defect in the tested area will allow gamma rays or photon electromagnetic radiation to expose the film. Over 200 cases of mishandling, misappropriation, or unwitting exposure to IRDs have been reported since 1942. If handled improperly, IRDs represent a rare but potentially devastating cause of radiation exposure in occupational environments.

\section{What units and definitions are used when discussing radioactivity?}

A substance that is radioactive is unstable and undergoes spontaneous disintegrations that result in the emission of energy. The

Keywords: radiation injury, REAC/TS, radionecrosis, radiography camera, iridium-192

Notes: There was no outside funding of any kind used in this study.

Corresponding author: Christina Hernon, Department of Emergency Medicine, University of Massachusetts Memorial Medical Center, Worcester, MA. Email: chh@gmail.com 


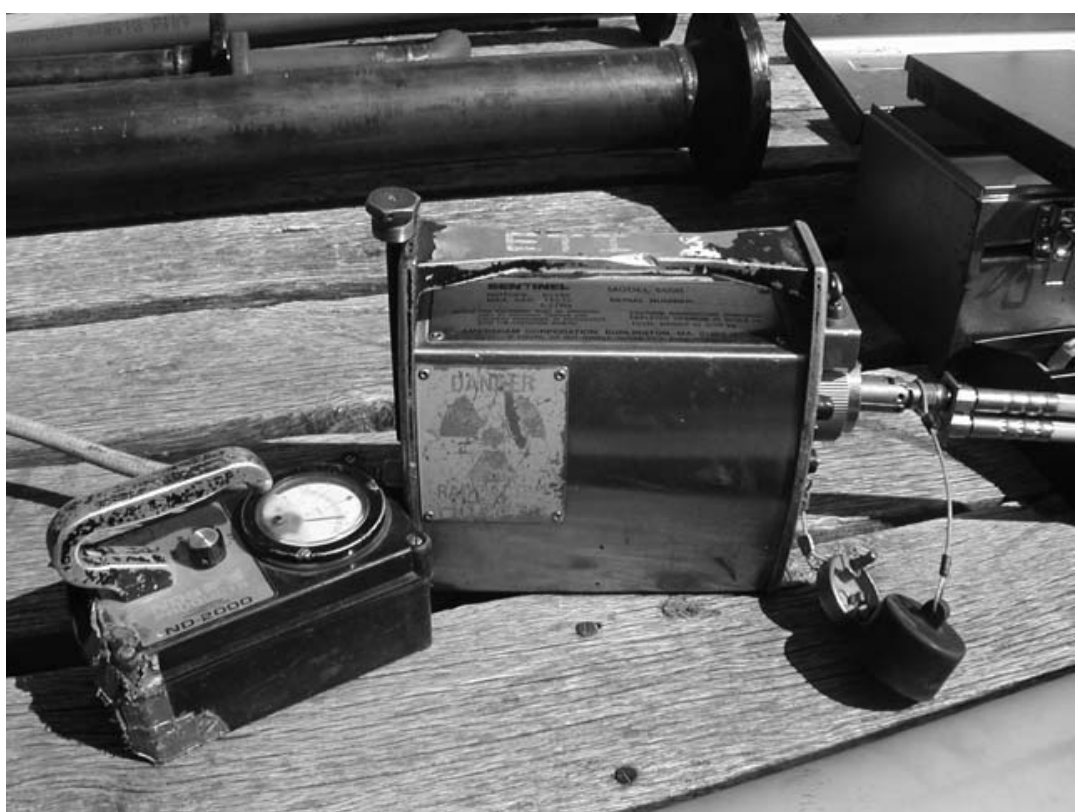

Figure 1. Iridium-192 Isotope Camera [Reprinted with permission by Larry R. Ewer, C.W.I., President, ETI Ewer Testing and Inspection, Inc. www.etitesting.com]

number of disintegrations per second is a measure of radioactive activity. A curie (Ci) is the amount of a given radionuclide that undergoes $3.7 \times 10^{10}$ disintegrations/second. The SI unit (International System of Units) of the becquerel (Bq) is one disintegration/second. Therefore, a curie is equivalent to $3.7 \times 10^{10}$ bequerels.

The three most common types of ionizing radiation are alpha particles, beta particles, and gamma rays.

Alpha radiation occurs when the equivalent of a helium nucleus (two protons plus two neutrons) is emitted from an unstable nucleus. Alpha particles have low penetrating power, being stopped by skin or a sheet of paper, and travel only a few centimeters through air. However, they easily transfer energy and are considered an internal hazard, whether the radiation source is ingested, injected, inhaled, or transferred to a wound that becomes contaminated.

An example of alpha decay is ${ }^{238} \mathrm{U} \rightarrow{ }^{234} \mathrm{Th}+{ }^{4} \mathrm{He}$ (alpha).

Beta radiation occurs when a beta particle, which has the mass and charge equivalent to an electron, is emitted from an unstable nucleus. It has moderate penetrating power, traveling up to a few meters in air and a few millimeters in biological tissue. It can be stopped by 20 sheets of paper or a piece of plexiglass.

An example of beta decay is ${ }^{14} \mathrm{C} \rightarrow{ }^{14} \mathrm{~N}+\mathrm{e}^{-}$(beta) + neutrino.
Gamma radiation occurs when a gamma ray (electromagnetic energy only, without mass) is emitted. It is high energy and has great penetrating power, able to travel many meters in air and deep into biological tissue. It can be shielded with lead or concrete.

An example of gamma decay is ${ }^{192} \mathrm{Ir} \rightarrow{ }^{192} \mathrm{Ir}+$ energy (gamma).

The amount of emitted radiation energy traveling through air is measured in roentgens (R). Each roentgen is the amount of gamma or $\mathrm{x}$-rays required to produce ions resulting in a charge of 0.000258 coulombs/kilogram $(\mathrm{C} / \mathrm{kg})$ of air under standard conditions. When radiation interacts with biological tissue, the dose of energy deposition is measured in rads (radiation, absorbed dose). The rad is defined as an absorbed dose of 100 ergs per gram, which is equivalent to $0.01 \mathrm{~J} / \mathrm{kg}$ of tissue. (Under typical conditions, one roentgen of radiation produces one rad of energy deposition; rads are the more clinically relevant measure, especially since the roentgen unit is only applicable to x-rays and gamma-rays). The gray (Gy) is the SI unit of radiation absorbed dose; each gray is equivalent to one hundred rads $(1 \mathrm{~Gy}=100 \mathrm{rad})$, or $1 \mathrm{~J} / \mathrm{kg}$ tissue. The amount of biological damage/risk per absorbed dose is measured in rem (radiation equivalent, man), or in SI units of sieverts (Sv). Similar to the relationship between rads and grays, each $\mathrm{Sv}=100$ rem. The amount of biological damage is proportional to a Quality Factor (QF) that varies depending on the type of radiation. For example, with beta and gamma radiation, the $\mathrm{QF}=1$, so each $\mathrm{rad}=1 \mathrm{rem}$. With internal alpha radiation, however, the $\mathrm{QF}=20$ 
TABLE 1. Terms for Exposure, Dose, and Risk Amount

\begin{tabular}{llll}
\hline Term: & Indicates: & Old Units & SI Units \\
\hline Exposure & lonization & roentgen (R) & coulomb/kg \\
Absorbed Dose & $\begin{array}{l}\text { Energy } \\
\text { Deposition }\end{array}$ & $\begin{array}{l}\text { rad (radiation, } \\
\text { absorbed dose) }\end{array}$ & $\begin{array}{l}\text { gray (Gy) } \\
(1 \mathrm{~Gy}=100 \mathrm{rad})\end{array}$ \\
\hline Dose Equivalent & $\begin{array}{l}\text { Biological } \\
\text { damage/risk }\end{array}$ & $\begin{array}{l}\text { rem (radiation } \\
\text { equivalent, man })\end{array}$ & $\begin{array}{l}\text { sievert (Sv) } \\
(1 \mathrm{~Sv}=100 \mathrm{rem})\end{array}$ \\
\hline
\end{tabular}

and each $\mathrm{rad}=20$ rem, indicating that alpha radiation has a 20 -fold greater risk of biological damage (with internal contamination) for the same amount of absorbed dose (See Tables 1 and 2).

Isolated irradiation is the exposure to radiation. Contamination involves the presence of either external or internal radioactive material. If contamination occurs, additional exposure to radiation will occur until the particles are removed, a process referred to as decontamination. Patients who have been irradiated do not emit further radiation, whereas contaminated patients may present a

\section{TABLE 2. Glossary of Terms Relative to Radiation}

\begin{tabular}{|c|c|}
\hline Radioactive & $\begin{array}{l}\text { Property of substances in which spontaneous disin- } \\
\text { tegrations of nuclei results in emitted (radiation) } \\
\text { energy. Emitting energy from decaying atomic } \\
\text { nuclei }\end{array}$ \\
\hline Alpha Radiation & $\begin{array}{l}\text { Type of radiation in which an alpha particle (which } \\
\text { is equivalent to a helium nucleus) is emitted. Low } \\
\text { penetrating power (stopped by skin or paper) and } \\
\text { short range. Can be very dangerous when intro- } \\
\text { duced into the body. }{ }^{238} \mathrm{U} \rightarrow{ }^{234} \mathrm{Th}+{ }^{4} \mathrm{He} \text { (alpha) }\end{array}$ \\
\hline Beta Radiation & $\begin{array}{l}\text { Type of radiation in which a beta particle (which } \\
\text { has the mass and charge equivalent to an electron) } \\
\text { is emitted. Medium to intermediate penetrating } \\
\text { power (stopped by } 20 \text { sheets of paper) may pene- } \\
\text { trate less than an inch into skin. Range in air of } \\
\text { inches to feet. }{ }^{14} \mathrm{C} \rightarrow{ }^{14} \mathrm{~N}+\mathrm{e}^{-} \text {(beta) + neutrino }\end{array}$ \\
\hline Gamma Radiation & $\begin{array}{l}\text { Type of radiation in which a gamma ray (electro- } \\
\text { magnetic energy only; no particle) is emitted. High } \\
\text { energy, short wavelength, most penetrating } \\
\text { (stopped by lead or concrete) } \\
\text { 192Ir } \rightarrow \text { 192Ir + energy (gamma) }\end{array}$ \\
\hline Activity & Number of disintegrations per second \\
\hline curie $(\mathrm{Ci})$ & $\begin{array}{l}\text { Amount of radionuclide that undergoes } 3.7 \times 10^{10} \\
\text { disintegrations/second }\end{array}$ \\
\hline becquerel (Bq) & $\begin{array}{l}\text { Amount of radionuclide that undergoes } \\
1 \text { disintegration/second (SI unit) }\end{array}$ \\
\hline Exposure & $\begin{array}{l}\text { May be direct to a certain body part, or may be } \\
\text { whole body irradiation }\end{array}$ \\
\hline Deterministic Effects & $\begin{array}{l}\text { Dose-determined effects, which may appear } \\
\text { acutely or be delayed }\end{array}$ \\
\hline Stochastic Effects & $\begin{array}{l}\text { Long term chance effects, not dose-determined, } \\
\text { such as increased cancer risk after radiation expo- } \\
\text { sure. Greater dose does not mean worse cancer. }\end{array}$ \\
\hline
\end{tabular}

radiation risk to others. Reduction of exposure depends upon minimizing time of exposure, increasing the distance from the radioactive source, increasing shielding, and minimizing the quantity of radioactive material.

\section{Case Continuation}

A Medical Toxicologist on call contacted the 24/7 hotline of the Radiation Emergency Assistance Center/Training Site (REAC/TS) at the Oak Ridge Institute for Science and Education (ORISE) in Tennessee; the Medical Toxicologist on call asked for management recommendations and prognosis information (Emergency contact number \#: 1-865-576-1005). If accurate, a local exposure to the hands of 18,000 rads could result in severe injuries to extremities and potentially require amputation. Patients were advised to return for evaluation if any new symptoms developed.

\section{What is the expected time course of radiation-induced illness, and what signs and symptoms may be expected?}

Large doses of radiation do not produce immediate death or incapacitation unless accompanied by concurrent explosive force or thermal injury. Isolated radiation exposure produces a dosedependent progression of symptoms that take from a half-anhour to a few weeks after the exposure event. After a massive exposure, death can occur in as little as six hours (See Table 3).

Acute radiation injury may be systemic from whole body irradiation (WBI) or significant partial body irradiation (PBI), both of which may result in Acute Radiation Syndrome (ARS). Acute radiation injury can also result from direct, local exposure (Tables 3 and 4). Effects may be deterministic, in which a greater dose produces a greater injury (whether acute or delayed, local or systemic), or they may be stochastic, in which exposure increases the risk of delayed chance effects, such as increased cancer risk. Deterministic effects in humans are measured using rads or grays, and stochastic effects in humans are measured using rems or sieverts.

Systemic or local radiation exposure produces clinical courses with comparable timelines. Prodromal symptoms appear within 0-48 hours, followed by a latent period of hours up to 21 days. Manifest illness may appear within hours to 30 days, and death

\section{TABLE 3. Acute Radiation Symptoms}

Time to Onset of Symptoms

\begin{tabular}{ll}
\hline Nausea, vomiting & $1 / 2-48$ hours \\
\hline Lymphocyte depletion & Hours to days \\
\hline Immunosuppression & $7-30$ days \\
\hline Granulocytosis & $1-7$ days \\
\hline Thrombocytopenia & $15-30$ days \\
\hline Granulocytopenia & $15-30$ days \\
\hline Death from shock & $6-48$ hours \\
\hline
\end{tabular}


TABLE 4. Whole Body Irradiation Effects

Acute Radiation Syndrome

\begin{tabular}{|c|c|c|}
\hline \multicolumn{3}{|c|}{ Acute Radiation Syndrome } \\
\hline \multicolumn{3}{|l|}{ Dose (rads) } \\
\hline $0-100$ & Subclinical & minimal or no effect \\
\hline $100-800$ & Hematopoietic & marrow suppression \\
\hline$\sim 300$ & Cutaneous & local effects \\
\hline $\begin{array}{l}10 \% \text { vomit at } 100 \\
1 / 3 \text { rd vomit at } 200 \\
2 / 3 \text { rd vomit at } 350 \\
95 \% \text { vomit at } 600 \\
100 \% \text { vomit at } 900-1,000\end{array}$ & Gastrointestinal & $\begin{array}{l}\text { nausea, vomiting, } \\
\text { diarrhea }\end{array}$ \\
\hline$\sim 600$ & Respiratory & ARDS-like; untreatable \\
\hline$>3,000$ & Cardiovascular/CNS & "unsurvivable" \\
\hline \multicolumn{3}{|c|}{ LD50 $=350-400$ rads (whole body irradiation) } \\
\hline
\end{tabular}

TABLE 5. Local Irradiation Effects

\begin{tabular}{lll}
\hline \multicolumn{2}{c}{ Acute Local Radiation Injury } \\
\hline Dose (rads) & Sign & Onset \\
\hline 300 & Epilation (hair loss) & $\sim$ day 17 \\
\hline 600 & Erythema & Minutes to weeks \\
\hline $1,000-1,500$ & Dry desquamation & $2-3$ weeks \\
\hline $2,000-5,000$ & Wet desquamation & $2-3$ weeks \\
\hline$>5,000$ & Radionecrosis, deep ulceration & variable \\
\hline
\end{tabular}

or recovery occurs within hours to more than 60 days. There is a large degree of overlap between these phases, but they generally progress in the order noted. With larger exposures, the time to onset of symptoms is shorter, and the progression is more rapid.

\section{How can one estimate radiation exposure?}

For gamma and x-rays, the risk of injury is related to the distance from the source of exposure. Calculations and equations required to derive an estimate of radiation exposure are complex mathematical functions that are the basis of the career of a Health Physicist, but the basic dosimetry calculations that give clinically relevant information are easy to utilize. Several data points are needed: time of exposure, distance from radioactive source, measure of radioactivity (curies or becquerel), and a constant that may be found in a radiation reference resource/book. Regardless of units, this constant for gamma rays is always described in terms of roentgen per time per radioactivity at a certain distance. For example, the gamma constant for iridium-192 may be written several ways, such as $5.2 \mathrm{R} / \mathrm{hr} / \mathrm{Curie}(\mathrm{Ci})$ at 1 foot or $4.8 \mathrm{R} / \mathrm{hr} / \mathrm{mCi}$ at 1 centimeter. (For our purposes, 1 roentgen $\sim 1$ rad.) In addition, the degree of exposure is inversely related to the

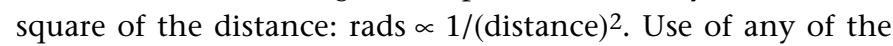

gamma constants will give dose estimates that are of similar magnitude. The initial calculations for the patients from this case will be used as an example.

First calculation:

Two patients held the end of the tube 0.25 inches from the source (93.4 curie iridium-192) for one minute.

Gamma constant $=5.2 \mathrm{R} / \mathrm{hr} / \mathrm{Ci}$ at 1 foot

For a $93.4 \mathrm{Ci}$ source:

$93.4 \mathrm{Ci} \times 5.2 \mathrm{R} / \mathrm{hr}=486 \mathrm{R} / \mathrm{hr}$ at 1 foot

For 1 minute:

$486 \mathrm{R} / \mathrm{hr}($ at 1 foot $) \times(1 / 60 \mathrm{th}$ of $1 \mathrm{hr})=8.1 \mathrm{R}($ at 1 foot $)$

At 0.25 inch:

$0.25^{\prime \prime} \times 1$ foot $/ 12$ inches $=0.0208$ feet

$8.1 \mathrm{R} / \mathrm{min}$ (at 1 foot) $\times 1 /$ distance $^{2}$

$=8.1 \mathrm{R} / \mathrm{min}($ at $1 \mathrm{foot}) \times 1 /(0.0208 \mathrm{feet})^{2}=18,700 \mathrm{rads}$

\section{Case continuation}

The next day, discussion between the employer's Radiation Safety Officer and REAC/TS resulted in an initial reconstruction of the event. The re-enactment led us to conclude that two of the patients (ages 63 and 40) handled the source for a minute each and were in the presence of the source for 2-3 minutes. The third patient, age 40 , was $2-3$ feet behind the other workers for 2-3 minutes. Because none of the patients had any acute symptoms, they agreed that the estimated exposure was probably not as high as the stated 18,000 rads and that direct doses to the hands were probably between 2,000-3,000 rads for the two patients with closest contact. These two patients were treated with pentoxyphylline and a week-long tapering dose of methylprednisolone. Also, serial color photographs were recommended.

\section{How serious is an "18,000 rad" exposure to the hands?}

A direct dose greater than 5,000 rads to the hands would result in radionecrosis and deep ulceration, regardless of the combination of distance, time of exposure, or strength of the radionuclide. With an exposure of 18,000 rads, erythema and pain would be expected within hours to days and followed by rapid and severe progression of symptoms from days to weeks; partial amputation of the hand would probably be required. Depending on the duration of exposure and location on the body, profound local radiation injury may require aggressive management.

In 1999, a similar radioactive source from a radiography camera was placed in a Peruvian welder's pocket for about six hours. Pain was noted four hours into the exposure, and local erythema of the skin was noted shortly after exposure ended. Ongoing radionecrosis mandated that a hemipelvectomy ultimately be performed. In the case of our patients, the absence of early progression suggested that the initial dose calculations were excessive. The lack of any delayed findings afterwards supported this observation. 


\section{Case Continuation}

All three patients received follow up with a hematologist familiar with radiation injuries and illnesses, and serial ophthalmologic evaluations to assess for radiation-induced cataracts were performed.

Four days after the incident, dosimeter results indicated Whole Body Exposure of 4.2-4.8 rads for the patients with close contact and approximately 0.4 rads for the third patient. Six days after the incident, the patients remained asymptomatic and participated in hands-on reenactments. The reenactments demonstrated that time of exposure was approximately half of previous estimates and that the distance of the source tip was further than previously estimated. This new information contributed to a new acute dose estimation of approximately 3,000 rads to the hands.

Approximately three months after the exposure, all patients remained asymptomatic with normal complete blood counts. All workers have had cytogenetic biodosimetry evaluation for future risk of stochastic effects. Despite an apparently injury free outcome, all three patients described psychological trauma (such as headache, insomnia, and anxiety) from this exposure.

\section{How can dose rate and exposure calculations aid management if they can be inaccurate?}

Dose calculations are often revised as the clinical course redefines the degree of exposure. Initial estimates are often conservative; they assist in predicting clinical course, determining therapeutic interventions, and supporting patient education. Initial dose estimates also aid in planning observations and long-term risk assessments since brief, acute exposure often produces minimal or no symptoms. Additional information from dosimeters, samplings, and reenactments may refine the data points and permit more accurate exposure calculations.

Important data regarding dose calculations are generated by radiation dosimeters that measure an accumulated dose. These devices are found in several different forms, such as a film badge, pocket dosimeter, or extremity monitor. They can be analyzed to determine irradiation relative to where the dosimeters were located on the person, which may be distinct from the mostexposed body site. Some dosimeters possess a real-time read-out of current exposure and will sound an alarm if a pre-set exposure limit is reached. The most common dosimeters require analysis to determine exposure, and results are usually delayed by a few days. In the event of contamination with radioactive materials, samples collected from the patient or patient's clothing may be analyzed to determine risk of exposure or risk of internal contamination, which may guide therapy with certain chelating agents or protective iodine supplementation. As in our patients, reenactments are important tools to approximate exposure. Regardless, a conservative approach is prudent because small variations in the data points have important consequences concerning risk for injury.

The reenactment identified that our patients held the guide tube at least 1 inch from the source, instead of adjacent to the source, as initially believed. The calculation therefore changes in a clinically significant manner:

\section{Revised Calculation:}

Gamma constant $=5.2 \mathrm{R} / \mathrm{hr} / \mathrm{Ci}$ at 1 foot

For a 93.4 Ci source:

$93.4 \mathrm{Ci} \times 5.2 \mathrm{R} / \mathrm{hr}=486 \mathrm{R} / \mathrm{hr}$ at $1 \mathrm{foot}$

For 1 minute:

$486 \mathrm{R} / \mathrm{hr}($ at 1 foot $) \times(1 / 60 \mathrm{th}$ of $1 \mathrm{hr})=8.1 \mathrm{R}($ at 1 foot $)$

\section{At 1 inch:}

$1^{\prime \prime} \times 1$ foot $/ 12$ inches $=0.083$ feet

$8.1 \mathrm{R} / \mathrm{min}$ (at 1 foot) $\times 1 /$ distance $^{2}$

$=8.1 \mathrm{R} / \mathrm{min}($ at 1 foot $) \times 1 /(0.083 \text { feet })^{2}=1,175$ rads

(instead of $>18,000$ )

At this level of exposure, dry desquamation and possibly wet desquamation are potential clinical outcomes, but dry or wet desquamations are less severe than radionecrosis. Ultimately, however, the patient's clinical progression provides indirect evidence of actual exposure. If no symptoms develop within the first few days, a massive exposure unlikely occurred. Weeks of progression help determine a realistic measure of exposure.

\section{How should an acute radiation exposure be managed?}

In this case, the radioactive source was iridium-192 sealed in a stainless steel enclosure that prevented contamination. The radioactive gamma rays passed through the enclosure and overlying guide-tube, putting these three patients at risk of local and whole body irradiation but without any risk of contamination. (If contamination had occurred, soap and water is usually adequate to remove any radioactive materials from the skin surface.) There was no hazard to treating personnel or the facility itself. Acute management consisted of determining the extent of exposure and potential risk, baseline medical evaluation, anticipatory guidance, and prompt follow up with hematology and ophthalmology.

Other considerations affect acute management decisions and utilization of resources. The type of event (accidental or intentional), the number of patients affected, the presence of contamination, and severity of acute injury all contribute to the ability to manage an incident with local resources. Regardless of the type of exposure, apprehension of first-line health care personnel regarding personal risk is common and understandable. Psychological trauma, which often affects patients, caregivers, and families, should also be anticipated, identified, and treated.

The Poison Control System was utilized as an initial resource by laypersons, medical personnel, and state public health officers-indicating that toxicologists need easily accessible information to aid in the management of a radiation exposure. The Radiation Emergency Assistance Center/Training Site (REAC/TS) out of the Oak Ridge Institute for Science \& Education (ORISE) in Oak Ridge, Tennessee offers guidance, recommendations, and assistance regarding radiation emergencies and was instrumental in managing these patients. In addition to preliminary phone consultation, they offered continuing recommendations for reenactments and medical follow up. 
Occupational radiation exposure may present physicians with a perplexing array of outcomes, definitions for exposure, and concerns of patients and caregivers. Early conservative assessment of risk can lead to aggressive but appropriate interventions that may be refined as improved exposure data is obtained. National resources, such as REAC/TS, are an important source of information and support for medical toxicologists who manage these demanding cases.

The authors have no potential conflicts of interest to report.

\section{REFERENCES}

1. Radiation Emergency Response and Dose Assessment Program, Radiation Emergency Assistance Center/Training Site
(REAC/TS), Oak Ridge Institute for Science and Education (ORISE), Oak Ridge, TN. March 28-31, 2006.

2. Photo reprinted with permission from http://www .etitesting.com/ETI_Testing/Industrial_Radiography/Industrial_ Radiography/industrial_radiography_1.html, accessed July 4, 2006.

3. Berger ME, Christensen DM, Lowry PC, Jones OW, Wiley AL. Medical Management of radiation injuries: current approaches. Occupational Medicine 2006;56:162-172.

4. International Atomic Energy Agency. Diagnosis and Treatment of Radiation Injuries. Safety Report Series No. 2. Vienna: IAEA, 1998.

5. Peter RU, Gottlober P. Management of cutaneous radiation injuries: diagnostic and therapeutic principles of the cutaneous radiation syndrome. Mil Med 2000;167: 110-112. 